\title{
DO SOFRIMENTO REDENTOR AO EXERCÍCIO REDENTOR: UMA BREVE TRAJETÓRIA DO CORPO
}

\author{
Braulio Amaral Lourenço \\ Professor de Educação Física da Rede \\ Municipal de Ensino de Porto Alegre \\ albraulio@gmail.com \\ Altemir de Oliveira \\ Professor de Educação Física da Rede \\ Municipal de Ensino de Porto Alegre \\ oaltemir@hotmail.com
}

RESUMO: Este texto tem como objetivo articular prática de exercícios físicos, concepções de corpo e tecnologias de poder. Para isso, esboçamos uma trajetória do corpo desde as sociedades de soberania, passando pelas sociedades disciplinares até as sociedades de controle. Nesta abordagem, o conceito de tecnologia política do corpo é apresentado como um mecanismo proveniente da interação entre fatores políticos, culturais e religiosos.

Palavras-chave: Tecnologia de poder. Atividade física. Corpo. 
O corpo e o exercício físico são abordados neste texto como manifestações culturais sujeitas às estruturas de poder, em seus devidos contextos, conforme Foucault (1999), ocorrendo desde as sociedades de soberania, passando pelas sociedades disciplinares até as sociedades de controle (VAZ, 2002; DELEUZE, 1998). Assim sendo, primeiramente o sofrimento e a morte eram tratados como espetáculo e a tônica do poder estava no direito do soberano de poder matar. Depois, com a valorização da vida e a mentalidade utilitária das instituições de confinamento, o corpo-força, treinado a serviço do Estado, substituiu, na escala de poder, o corpo torturado. Já no mundo contemporâneo da sociedade de controle, o corpo-força cede espaço ao marketing do corpo cultuado e saudável alcançado pela prática de exercícios físicos e pelo protagonismo do saber médico.

Neste trabalho, pretendemos articular prática de exercícios físicos, concepções de corpo e tecnologias de poder, e, com isso, cumprir duas tarefas: primeiramente traçar uma trajetória do corpo desde as sociedades de soberania até as sociedades de controle, e, por conseguinte, apontar as mudanças na abordagem do corpo neste mesmo período, observando os critérios de cada tecnologia de poder. Sem a preocupação de apresentar algo inteiramente novo ou de esgotar as discussões em torno do assunto, procuraremos também chamar a atenção para a permanência na atualidade dos conhecidos mecanismos de controle fundamentados a partir da cultura judaico-cristã. Mecanismos esses que Foucault (2004) chamou de tecnologia política do corpo. Não que tudo permaneça exatamente igual ao que sempre foi, mas mostrar esse esforço das estruturas de poder, recriando estratégias para manter a capacidade de posicionar os sujeitos.

\section{Tecnologias de Poder e Concepções de Corpo}

Considerando que as tecnologias de poder influenciaram os modelos de sociedades e, consequentemente, as concepções de corpo, procedemos à abordagem resumida destes modelos: das sociedades de soberania, passando pelas sociedades disciplinares até as sociedades de controle.

De períodos mais remotos da história até a revolução industrial, tínhamos, nas sociedades de soberania, a manutenção do poder e o controle da população a partir da 
idéia do "fazer morrer ou deixar viver". Cabia ao soberano, como detentor dos direitos de vida e de morte, e como um representante de Deus, decidir pelo destino de cada indivíduo. Neste contexto, segundo Foucault (2004), o corpo era o alvo principal das punições, já que a ele (corpo do indivíduo) era dirigida a tortura ou a pena capital. Assim sendo, dada que a vida dos indivíduos não era uma concessão proporcionada pelo soberano, e como esse não tinha ingerência direta e real sobre a vida em si, a fim de consumar o seu poder, nessa conjuntura ele precisava matar. Ao assim fazê-lo com alguns indivíduos e permitindo a continuidade da vida para outros, ele cumpria, ao seu modo e aos olhos da população, o direito de deixar viver. Pela possibilidade de matar do soberano, o deixar viver logo adquiria sentido e tornava-se uma prerrogativa de quem exercia o poder. Deve ficar sublinhado que a lógica deste sistema estava assentada no poder de matar do soberano.

Nos séculos XVII e XVIII, surgem novas técnicas de poder centradas não mais no direito de vida e de morte, como era predominante nas sociedades soberanas. Embora o corpo continuasse sendo espaço de inscrições do poder político e religioso, ele passa a ser considerado também de forma individual. Foucault (1999) classificou essa perspectiva como sendo um anátomo-poder, baseado numa disciplina que seria expandida à multiplicidade dos homens, com a finalidade de oportunizar a existência de corpos individuais passíveis de serem vigiados, treinados, utilizados e, ocasionalmente, punidos. Por assim dizermos, essa tecnologia de poder se destinava a aumentar a força de trabalho através do exercício e do treinamento. Portanto, em comparação com o poder exercido pelo soberano, há um primeiro movimento no deslocamento da lógica de exercício do poder, ou seja, do fazer morrer para o fazer viver.

Um testemunho dessa alteração de mentalidade foi descrita por Perrot (2000), em "O Inspetor Bentham", quando abordou o trabalho do filósofo e jurista inglês e o contexto do século XVIII sob a ótica de uma filosofia utilitarista. Nesse trabalho, a autora apresentou um parecer do próprio Bentham, em que esse discordava da pena de morte ao considerar que "longe de se converter em proveito, essa pena é uma perda, um desperdício daquilo que constitui a força e a riqueza de uma nação: o número de homens." (BENTHAM apud PERROT, 2000 p. 121). 
A partir disso, na segunda metade do século XVIII, parece-nos haver dois fatores que estimularam uma nova mudança, alterando a técnica disciplinar sem, no entanto, eliminá-la. O primeiro fator seria uma culminância de eventos na história da ciência iniciados desde o século XVI, que foram denominados de Revolução Científica. O segundo fator (decorrência do primeiro) seria a Revolução Industrial, que assinalava o surgimento de um novo sistema de produção - o capitalismo.

Considerando os dois fatores, podemos inserir na discussão a contribuição de Sibilia (2002) que comenta sobre a reinvenção do relógio. Como é sabido, o relógio já existia muito antes da Revolução Industrial, contudo, pela necessidade de sincronizar o trabalho nas fábricas, o produto adquiriu relevância. Consideramos que o relógio simboliza simultaneamente uma face da Revolução Industrial e uma face da Revolução Científica. Na primeira, ao introduzir o reordenamento do tempo e a ocupação do espaço pela lógica racional de produção, alterou a lógica de trabalho baseada nos ciclos da natureza e no biorritmo do corpo. Na segunda, ao estabelecer a analogia, levando-a às ultimas consequências, entre corpo humano e máquina, legitimou o entendimento de que o funcionamento de um era semelhante ao outro, logo poderia ser regulado por esta norma.

Sendo assim, impulsionada pelas demandas criadas pelo então sistema emergente de produção, surge uma tecnologia de poder denominada por Foucault (1999) de "biopolítica", a qual englobou, integrou e modificou, de certo modo, a noção de anátomo-política, baseada na disciplina individual dos corpos. Essa tecnologia propôs uma relação de poder, na qual, a partir da abordagem pela multiplicidade, os corpos seriam individualmente atingidos.

Poderíamos mesmo dizer, que o anátomo-poder correspondia às necessidades voltadas para o controle dos corpos individualmente nas microrrelações e que a biopolítica correspondia ao âmbito das macrorrelações, dirigia-se ao homem-vivo ou homem-espécie ${ }^{1}$. Desse modo, temos o segundo movimento no deslocamento da lógica de exercício do poder: a reafirmação de uma tecnologia baseada no fazer viver, como ideia central.

A partir da segunda metade do século XX, porém, segundo Costa (2004), os meios de ação das sociedades disciplinares entraram em declínio e ocorreu o surgimento da sociedade de controle. Vaz (2002) afirma que a crise que se instalou nesse período, se

\footnotetext{
${ }^{1}$ Expressão de Foucault, 1999.
} 
completou nos anos 90 e, como consequências, ocorreram mudanças nas técnicas de poder, no sentido da vida proposto pela cultura e na visão de sujeito.

Vaz (2002) sugere que há dois vetores de mudança na experiência do corpo, que, por vezes, podem não apontar na mesma direção nessa nova configuração, o que colocou a necessidade de um terceiro fator. Explica o autor que, no primeiro vetor, temos as novas tecnologias, que alteraram a experiência do corpo, ao exercerem uma mediação generalizada e que, ao modificarem as questões éticas, nas quais nos pautamos para nos constituirmos como sujeitos, também podem oportunizar diversas experiências que transformariam o processo de subjetivação. No segundo vetor, temos a transformação do capitalismo, que tem entre suas estratégias estimular os sujeitos ao consumo por muito tempo e, com isto, controlá-los através de um padrão de consumo. Aqui entraria o terceiro fator da relação que promoveria o ajuste entre ambos, pois o caráter restritivo do segundo vetor não poderia conviver com a infinidade de possibilidades do primeiro. Aparece, assim, a transformação nas relações de poder, a qual é apontada como sendo a passagem da norma - marca registrada das sociedades disciplinares - ao risco.

O risco é um conceito importante na dinâmica da chamada sociedade de controle e inseri-lo na discussão do texto nos possibilita pensar as alterações e as relações entre sofrimento (ocasionado pelas punições), prática de exercícios e a trajetória do corpo, bem como as noções de saúde e alguns conceitos oriundos da cultura judaico-cristã que continuam tendo influência nos mecanismos de poder.

\section{Do sofrimento redentor ao exercício redentor}

Um elemento de notável importância para fins de argumentação e entendimento é a função exercida pela concepção de divindade. Nas sociedades de soberania, ela estava em evidência e era personificada pela figura do soberano, assim sendo constituía-se um aspecto tido como natural na organização daquelas sociedades. Na anátomo-política e na biopolítica, embora a função tenha se modificado, a idéia da divindade continuava presente. Ela passou a não ser mais personificada na figura do soberano com seu caráter essencialmente punitivo, mas na onipresença das leis políticas e religiosas que atuavam de forma reguladora dos costumes. 
Com relação à sociedade de soberania, cabe salientar a ideia de sofrimento ao corpo presente nas práticas. No âmbito específico da religião, herança da Antiguidade e da Idade Média, os castigos ao corpo eram praticados com o intuito de fazer o então desviante redimir-se de suas faltas ou, para usar um termo associado historicamente à Idade Média, de suas heresias. Já no campo político-social, os castigos ao corpo, ocasionando o sofrimento ou a morte, cumpriam as funções de manter o poder do soberano.

O acusado, ao ser punido, carregava no corpo a culpa e as marcas do castigo, como, por exemplo, açoite e marcação com ferrete. O sofrimento, como se vê, não necessariamente lavava o acusado da infâmia, pelo contrário, poderia reforçá-la. Sendo assim, tanto o sofrimento físico em si no momento da punição, quanto as dores morais e psicológicas deveriam repercutir no corpo e na memória do acusado e também na memória da plateia². Portanto, tornava-se redentor o sofrimento não necessariamente para o sujeito castigado, mas certamente para o soberano que, através do suplício alheio, reafirmava seu poder sobre os súditos, cumprindo simbólica e moralmente sua parcela no direito de deixar viver. Temos com isso possivelmente, ainda de forma rudimentar e fisicamente ostensiva, um perfil de atuação baseado numa tecnologia de poder que produzia inscrições no corpo, denotando a existência daquilo que Foucault (2004) chamou de tecnologia política do corpo, ou seja, um saber do corpo e um controle de suas forças.

Nas sociedades disciplinares, com os avanços produzidos pelo conhecimento científico, além de o Estado e a Igreja terem posições políticas e sociais privilegiadas, a ideia de exercício do corpo com finalidades utilitárias, estéticas e morais começa a ser apropriada, tornando-se propaganda do poder instituído. Percorre o caminho inverso ao proposto pelas sociedades de soberania, mas mantém no corpo a marca do poder: antes, as cicatrizes como castigo pela afronta ao soberano, depois o corpo fortalecido e docilizado levando a mensagem do poder.

Tendo-se chegado à conclusão de que, dentro das mudanças na ordem econômica e social era um erro matar um homem, o investimento sobre o corpo não mais consistiria numa arte que se esmeraria em torturá-lo ou eliminá-lo e sim para fortalecê-lo (anátomopoder), e depois para protegê-lo de possíveis males (biopolítica). Portanto, nesse período,

\footnotetext{
${ }^{2}$ Termo utilizado intencionalmente, pois os castigos e até a morte eram práticas comparáveis a um espetáculo realizadas em espaço de domínio público.
} 
temos uma mudança conceitual de foco: do sofrimento legalizado infligido ao corpo, para os disciplinamentos institucionalizados do corpo.

A nova leitura do corpo alterava igualmente o modo como eram promovidas as punições, que deixaram de ser espetáculos públicos e alardeados para se tornar uma ação de caráter privado, em locais específicos (prisão). Assim as punições tornaram-se mais sutis, pretendendo atingir profunda e subjetivamente o acusado através de privações, coações e obrigações. Ocorre, desta forma, uma importante modificação: a culpa não mais estaria inscrita nas cicatrizes do corpo, mas em aspectos intangíveis do ser humano. Temos uma demonstração do papel decisivo existente na ideia de culpa nessa tecnologia de poder. Para Vaz (2002, p.08), "as técnicas de poder da disciplina são modos de produzir a culpa" e, não sendo suficiente internalizar a vigilância, urgia que cada um se julgasse e desejasse se julgar, segundo os valores sociais vigentes.

Outra alteração significativa na leitura do corpo e exemplo da mudança conceitual de foco seria que, enquanto nas sociedades de soberania o corpo parecia pertencer predominantemente aos rigores do poder político e religioso, nas sociedades disciplinares, ele passa a pertencer também à ciência, que era, em última análise, quem fundamentava o novo sistema. Isso pode ser comprovado em Vigarello (1995), quando analisa que as finalidades terapêuticas passaram a dividir as atenções com as finalidades corretivas e estéticas; e, em Fraga (2000), descrevendo que, no século XVII, tinham-se as preocupações com o corpo máquina (passível de adestramento), com o aumento de capacidades e aptidões, e com a ampliação da utilidade e da docilidade. A ideia do corpo útil e trabalhado socialmente como força se estende de fins do século XVIII, passa pelo século XIX e alcança o século $X X$, quando os mecanismos das sociedades disciplinares entram em declínio.

Segundo Vaz (2002), este seria um momento de passagem para uma ideia de corpo proposta entre o risco e o prazer (sociedade de controle), a qual pode ser comprovada pelo surgimento histórico de práticas esportivas. Poderíamos, inclusive, pensar uma articulação de fatores entre as tecnologias de poder, conceito de corpo e sistema de produção. Assim sendo, temos, nos esportes surgidos nas sociedades disciplinares, que o corpo era pensado como fonte de energia e movimento, o que corresponderia à fase do capitalismo para a concentração e a produção. Já nos esportes que surgem após a década de 50, no 
século $X X$, período de crise e de instalação da sociedade de controle, o corpo passa a ser pensado a partir do binômio risco-prazer, o que corresponderia à fase do capitalismo para a sobreprodução e para o mercado.

Nas sociedades de controle, como já referimos, há dois vetores de mudança na experiência do corpo (novas tecnologias e transformação do capitalismo) que, por não funcionarem necessariamente na mesma direção, deram origem a um terceiro fator: a transformação das relações de poder, propiciando a passagem da norma ao risco. Consideramos, porém, que dois outros fatores, de certa forma decorrentes dos vetores mencionados, também participam decisivamente do cenário desses acontecimentos. O primeiro aspecto a considerar seria a ascensão dos conhecimentos produzidos pelos estudos das áreas biomédicas, que impulsionaram as expectativas de vida para outro patamar em termos de duração e qualidade. O segundo aspecto a considerar, corroborando com Hall (1997), seria a questão da centralidade da cultura, verificada a partir do que o autor denominou de "virada (ou revolução) cultural"3.

Nesse contexto, localizamos mudanças importantes ocorridas na transição das sociedades disciplinares às sociedades de controle, no que se refere às proposições acerca da lógica de vida, do corpo, do exercício e da prática esportiva. Portanto, temos mais uma alteração conceitual no modo de gerir a vida e nos parâmetros responsáveis pela sua preservação. O exercício físico, que nas sociedades disciplinares já tinha uma função estratégica relacionada ao utilitarismo, na sociedade de controle parece ter sido elevado na hierarquia dos poderes. Talvez pudéssemos afirmar que nas sociedades disciplinares o exercício físico e o corpo eram simples engrenagens no sistema. Já na sociedade de controle, apesar de regulá-los, estabeleceu-se uma contradição dentro da qual o exercício físico e o corpo são protagonistas.

Com isso, desde as sociedades de soberania, passando pelas sociedades disciplinares e chegando à sociedade de controle, temos um deslocamento de concepção nas tecnologias políticas do corpo. Esse deslocamento, conforme descrevemos, partiu de uma ênfase no sofrimento do corpo como forma de redimir-se, atravessou o período compreendido entre o final do século XVIII e meados do século XX, enfatizando o corpo-força moldado para

\footnotetext{
${ }^{3}$ Segundo Hall (1997), o termo "virada cultural" se refere a uma mudança conceitual na abordagem da análise social contemporânea, a qual passou a conceber a cultura como uma condição constitutiva da vida social e não mais apenas como uma variável dependente.
} 
o trabalho e veio alcançar o século $\mathrm{XXI}$, no qual se passou a enfatizar os atributos joviais corpóreos. Com uma abordagem relativa à recente tecnologia de poder (sociedade de controle) relacionada às interfaces com o exercício físico, pretendemos no próximo tópico aprofundar estas articulações e completar a proposta deste texto.

\section{Exercício Físico Redentor: Saúde e Salvação}

Mesmo não sendo o foco do presente artigo a discussão sobre a influência da cultura na tecnologia política do corpo e no exercício físico, consideramos que ela participa na composição e entendimento do contexto da sociedade de controle. Desta forma, segundo Hall (1997), temos a questão da centralidade da cultura no século XX, bem como o que esse autor denominou de "virada cultural". Para ele, a "virada cultural" abrangeria dois aspectos: os aspectos "substantivos" e os "epistemológicos". Os substantivos seriam o lugar da cultura na estrutura da sociedade empírica de fato e um exemplo disto pode ser o aparecimento e a popularização de esportes de risco calculado. Já, no outro conjunto, os aspectos "epistemológicos" se referem à posição da cultura em relação às questões de conhecimento e conceitualização, bem como ao modo como a cultura participa e é usada para transformar a compreensão, explicação e modelos teóricos. Nesse caso, um exemplo poderia ser o que Vaz (2002) chamou de cientificização do cotidiano, que é apontada como um modo de garantir o ajuste entre os vetores tecnológico e econômico, e também de regular a tensão entre o prazer e o risco.

Ainda podemos considerar que a prática de exercícios e de esportes são manifestações culturais, que, na sociedade de controle, não só cumprem funções de promoção da saúde, atendendo a um critério médico e científico, mas também funções políticas, que assinalam a importância destas práticas como mecanismos de uma tecnologia de poder. No Brasil, no período conhecido como "ditadura militar" (de março de 1964 a março de 1985), alguns processos foram acelerados, estimulando, pois, a condução de uma situação de crise das instituições disciplinares para os novos parâmetros da sociedade de controle. Um exemplo disso, de acordo com Sant'Anna (1994), foi, no século passado, desde fins dos anos 60 e, principalmente, a partir de 1975, que "o suor entrou na moda" 4 . É também desse período

${ }^{4}$ Expressão da autora: Sant'Anna (1994, p.80). 
a estratégia de construir praças esportivas com o intuito de promover a concentração de público para a prática de exercícios, substituindo, assim, as concentrações de público com objetivos políticos. Esses fatos sugerem que o corpo e o esporte se tornaram espaço de propaganda do regime militar, além de representarem um novo investimento nas estratégias de tecnologia de poder. O corpo, a partir desse período, passa a assumir um protagonismo, que o desloca hierarquicamente nas configurações de poder do Estado.

Além disso, através do incentivo às práticas de exercícios, uma nova imagem do corpo parece ter sido gestada e veiculada: da saúde, da juventude, da beleza, da velocidade e da descontração. Mais do que estabelecer uma espécie de culto ao corpo, as inscrições que Ihe eram impressas carregavam mensagens que denotavam a influência do empresariado da época e as demandas do mercado. Quanto à perspectiva das demandas do mercado associadas às práticas de exercícios, com a colaboração do saber médico e a propaganda em torno do campeonato mundial de futebol de 1970, tais práticas de tempo livre se tornaram sinônimo de práticas de exercícios e esportivas. Desta forma, surgiu um novo mercado a ser explorado: a moda esportiva com produtos de vestuário e calçados apropriados em inúmeras opções de marcas. O corpo outrora alvo de castigos (inclusive capitais) na sociedade de soberania torna-se espaço de culto e investimento, ainda que fosse para mantê-lo, em todos os casos, dominado pelo Estado.

Mantendo o foco da abordagem na influência do empresariado e nas demandas do mercado, Deleuze (1998) considera que há correspondência entre as máquinas e certos tipos de sociedade. Dito assim, podemos cogitar que a popularização do computador, no final do século $X X$, seria uma comprovação do pensamento do autor, no que se refere à sociedade de controle. Um desdobramento possível, porém, em nossa opinião, é que o corpo, que já era treinado para trabalhar como máquina, tem sido mais recentemente abordado (seguindo na metáfora) com o intuito de substituir-lhe as peças supostamente em desacordo com o padrão estético. É o que se verifica, ao constatarmos o aumento de intervenções cirúrgicas neste sentido, corroborando então com a ideia de Vaz (2002) para quem o corpo tem se notabilizado pela capacidade de consumir e ser consumido. Essa sentença, contudo, guarda um paradoxo que parece acompanhar a lógica de mercado da sociedade de controle, a saber: também o corpo, para ser mantido belo e jovem, deverá 
consumir-se em alguma medida, com o intuito de tentar sobreviver à lógica da obsolescência.

A ênfase na prática de exercícios físicos e a busca do corpo idealizado parecem guardar consigo mais conteúdo político e cultural do que veríamos num primeiro olhar. Como exemplo dessa tese, podemos citar o debate de um antigo dilema filosófico: de um lado as posições ascéticas ou estoicas, e de outro, as posições hedonistas. Enquanto nas sociedades disciplinares as influências ascéticas ou estoicas ocupavam posições de evidência no sistema, na atual sociedade de controle, esse espaço passa a ser ocupado por influências hedonistas, nas quais, acompanhado da noção de risco, o prazer tornouse uma busca constante. Esse dilema, que, na atualidade aparece pendendo para o lado do hedonismo, para Lovisolo (2000) seria um componente importante nas explicações acerca das dificuldades encontradas para aumentar as taxas de praticantes, apesar das propagandas sobre os benefícios dos exercícios físicos. Consoante com esse autor, devemos lembrar que, na sociedade de controle, uma solução para esse dilema, quando relacionado à prática de exercícios físicos, seria bastante complexa, pois, nessa recente configuração, vivemos a partir das ideias de minimização dos esforços e maximização do prazer. Logo, o prazer, dentro dos parâmetros previstos pelo risco, tornou-se uma busca convencionada e legítima de hipersensações, haja vista vivermos em um mundo em que não há exterioridade de valores desde a crise das instituições tradicionais, tais como a família, a escola e a Igreja.

As noções de prazer e de risco são partes inextrincáveis de um jogo importante na sociedade de controle: o jogo da produção de subjetividades. Para Vaz (2002), o objetivo maior não é o sujeito verdadeiro e sim o processo de constituição desse sujeito. Neste sentido, podemos considerar que os mecanismos utilizados nesta tecnologia de poder aproveitaram o lastro construído pelas sociedades disciplinares, principalmente no que se refere às técnicas de culpabilizar. Segundo esse autor, seria possível estabelecer conexões entre a noção de risco e os conceitos de pecado e norma, reafirmando, assim, a influência da cultura judaico-cristã na cultura atual. Na dinâmica desse sistema, o processo de subjetivação pressupõe um condicionamento cultural de valores e crenças, que são constituídos por uma ideia de "dívida infinita" no interior do indivíduo, quando esse pensa em si mesmo e se propõe transformar-se. É caracterizada como "infinita", pois, no autoquestionamento ao 
qual é condicionado a realizar, o indivíduo é continuamente levado a pensar no que deve ser e fazer, porém não é educado para pensar no que pode.

Destacamos também Deleuze (1998), comparando e descrevendo o que na sua visão acontecia nas sociedades disciplinar e de controle. Tal autor afirmou que, na primeira, o indivíduo estava rotineiramente sendo moldado e movimentando-se de uma instituição de confinamento para a outra, o que caracterizaria a ideia de quitação aparente. Já, na segunda, ocorre o que o autor chamou de moratória ilimitada, na qual "nunca se termina nada" (DELEUZE, 1998, p.221) e os indivíduos viveriam dentro de estados metaestáveis e coexistentes de modulação, tais como a empresa, a formação e o serviço. Consideramos que esse estado de modulação diz respeito às questões da culpa e da dívida infinita, pois reforça nos indivíduos a ansiedade de manter-se na busca por algo (mesmo que não complete a experiência), sob pena de ser alijado no jogo da produção de subjetividades, cuja finalidade está diretamente relacionada ao consumo, no qual é exigido que os indivíduos se mantenham consumindo sem se consumirem por inteiro.

Assim sendo, retomando o foco na alteração substancial das funções do exercício físico e da visão do corpo promovida pelo Estado, parece-nos que tais funções desempenharam um papel ainda mais amplo na formulação, promoção e fixação do modelo ligado ao controle exercido através do cuidado com a saúde. Apesar da reconhecida relevância dessa discussão, não a abordaremos neste texto por não ser o foco do trabalho e por entender que Fraga (2005) já o fez em sua tese de doutorado.

Por isso, concordando com Fraga (2005), reconhecemos que havia outro objetivo implícito na tentativa de convencer o público de que as atividades compulsórias seriam uma forma de exercício. Nessa tentativa de convencimento também havia uma estratégia para se fazer presente no cotidiano dos indivíduos. Se nas décadas de 70 e meados de 80 do século passado a preguiça era a antítese do sistema, na última versão da sociedade de controle o sedentarismo ocupa este lugar. Portanto, ao praticar o exercício, ou realizar sua atividade compulsória, o indivíduo não só estaria sendo atendido na sua necessidade de pertencimento, como também cuidaria da sua própria saúde. Do ponto de vista da prática de exercício físico, este seria o grande prêmio: a conquista diária da saúde e sua manutenção. Nesta ideia se encontraria a salvação e o ideal de vida, como afirmou Sant' Anna (1994): 


\begin{abstract}
"A saúde ocupa hoje o lugar da salvação, e não é um termo oposto apenas ao ser doente, mas também ao ser improdutivo, fraco, feio e lento. A obtenção da saúde assemelha-se à conquista da própria vida e da possibilidade de estendê-la para além de quaisquer fatalidades". (p.101)
\end{abstract}

Tentando ampliar essa compreensão, mas focalizando no paradoxo da mensagem transmitida pelo marketing no exercício físico, podemos observar no sedentário talvez mais do que a figura da antítese do sistema. Ele poderia ser apontado como uma espécie de herege contemporâneo, na medida em que é um indivíduo cujo comportamento lembraria um desequilíbrio perigoso na relação prazer/risco. Isso colocaria o sedentário em falta com sua responsabilidade perante o sistema e a vida. Ao praticar exercícios físicos, estar-se-ia, de certa forma, contribuindo para o fazer viver, ao não praticá-lo, tornar-se-ia um sedentário, o que seria o equivalente ao deixar-se morrer. Neste sentido concordamos com Sant'Anna (apud FRAGA, 2005, p. 153):

'[...]'não dar conta' de si mesmo, em sociedades nas quais o 'si mesmo' se tornou um negócio de total responsabilidade de cada um, torna-se um novo fantasma, tão terrível quanto o antigo fantasma das culpabilidades escondidas a sete chaves."

A partir da citação acima e do que foi exposto ao longo do artigo, nota-se que, na sociedade de controle, vem ocorrendo uma importante articulação entre fatores, que propiciaram o surgimento de uma nova síntese de tecnologia política do corpo. Entre esses fatores se destacam o controle político, a influência dos saberes médico e biológico e a permanência de conceitos da cultura judaico-cristã. Apesar da conhecida crise das instituições disciplinares, entre essas a crise da lgreja desde o final do século passado, um comentário digno de registro é que podemos perceber nas estratégias políticas da sociedade de controle a nítida reinserção desses conceitos nos discursos promovidos, inclusive na prática de exercícios e de esportes.

\title{
Considerações Finais
}

Do objetivo principal deste artigo, que era essencialmente tentar realizar articulações entre prática de exercícios físicos, concepções de corpo e tecnologias de poder, destacaremos alguns comentários sobre questões fundamentais na dinâmica das tecnologias políticas do corpo. 
$\mathrm{Na}$ trajetória descrita sobre as concepções de corpo, procuramos evidenciar características pertinentes ao modo de exercer o poder em cada contexto. Concordando com Deleuze (1998), sobre a correspondência entre os tipos de máquinas e as sociedades, poderíamos dizer que há correspondência entre as concepções de corpo e tecnologias de poder.

Neste sentido, podemos lembrar que a transformação de regime do fazer morrer e deixar viver para o fazer viver e deixar morrer (FOUCAULT, 1999) assinalou uma mudança conceitual, cuja repercussão deslocaria a abordagem do corpo para outro patamar, no qual a prática de exercícios passou a ser adotada como estratégia. O "nascimento da prisão" (FOUCAULT, 2004) foi um componente importante nessa metamorfose em que o poder do governo, apesar de ter se tornado menos físico e violento, não necessariamente ficou menor, apenas mudou a forma de atuação. O poder, que era personificado pelo soberano, tornouse institucionalizado. Com isso, as instituições de confinamento, que eram encarregadas de organizar por onde e quando os indivíduos transitariam, moldavam e anotavam nos corpos as inscrições do poder através da norma. Quando essas instituições começaram a entrar em colapso em meados século XX, passamos a ter o período de instalação das sociedades de controle. Desta forma, foi acrescido um novo componente às estruturas de poder formadas predominantemente com fundamentos políticos e religiosos, ou seja, o saber médico que ao longo dos séculos XVIII e XIX foi conquistando espaço com a lógica utilitarista. Essa reconfiguração do poder e o contexto desses acontecimentos convencionadamente sinalizam o momento de passagem da norma ao risco. Foi também o período em que o poder tornou-se mais horizontalizado e a responsabilidade social do Estado foi transferida para o indivíduo, o qual, de acordo com o marketing da saúde, deveria aprender a "cuidarse".

Temos assim, portanto, uma versão dos desdobramentos sucessivos que apontam na atualidade para uma tecnologia política do corpo mais sutil, intangível e invisível relacionada à sociedade de controle, mas que opera profundamente nos indivíduos. Para ilustrar essa tese, citamos as articulações no poder entre fatores políticos, biomédicos e religiosos relacionados à propaganda da prática de exercícios físicos em larga escala desde os anos 1970. Esta estratégia permitiu que a prática de exercícios físicos, perante o poder instituído, 
assumisse significados comparáveis à prática de um culto religioso, suscitando, também, o culto de um corpo jovem e belo na sociedade de controle como uma espécie de imagem divinizada. Além disso, pensando a partir das ideias de Fraga (2005) e Sant'Anna (1994), o marketing da promoção da saúde, que a coloca em um nível comparável ao da salvação, além da incapacidade de se cuidar (da saúde) como algo digno de culpa, também faz com que na ideia de prática de exercícios físicos se encontrem elementos de uma concepção maniqueísta. Nesta relação, a prática de exercícios seria equivalente a ter saúde, amparo e praticar o bem. Já o não praticar exercícios seria equivalente ao sedentarismo e a uma incidência irresponsável de risco pessoal, o que significaria fazer o mal.

Por conseguinte, ao correlacionar sofrimento e exercício com o termo redentor, tentamos colocar em evidência uma alteração de mentalidade que seguia critérios religiosos, mas que claramente também atendia objetivos políticos. Dentro dessa ideia, convém lembrar que no final do século $\mathrm{XX}$, começo do período de predomínio dos mecanismos da sociedade de controle, o saber médico colaborou decisivamente na fundamentação da prática de exercícios físicos e na definição dessa tecnologia de poder.

\section{Referências}

COSTA, R. da. Sociedade de controle. São Paulo em Perspectiva, v.18, n.1, p. 161$167,2004$.

DELEUZE, G. Conversações. São Paulo: Editora 34, 1998.

FOUCAULT, M. Vigiar e punir: nascimento da prisão. 28ed. Petrópolis: Vozes, 2004. Em defesa da sociedade: curso no Collège de France (1975-1976). São Paulo: Martins Fontes, 1999.

FRAGA, A. B. Exercício da informação: governo dos corpos no mercado da vida ativa. UFRGS, 2005. Tese (Doutorado em Educação), Faculdade de Educação, Universidade Federal do Rio Grande do Sul, 2005.

FRAGA, A. B. Corpo, Identidade e bom-mocismo - cotidiano de uma adolescência bem comportada. Belo Horizonte: Autêntica, 2000. 
HALL, S. A centralidade da cultura: notas sobre as revoluções culturais do nosso tempo. Educação \& Realidade, Porto Alegre, v. 22, n², p. 15-46, jul./dez. 1997.

LOVISOLO, H. R. Atividade Física, educação e saúde. Rio de Janeiro: Sprint, 2000.

PERROT, M. O inspetor Bentham. In: SILVA, T. T. da (Org.). O panóptico. Belo Horizonte: Autêntica, 2000.

SANT'ANNA, D. B. de. O prazer justificado: história e lazer (São Paulo, 1969/1979). São Paulo: Marco Zero/MCT-CNPq, 1994.

SIBILLA, P. O homem pós-orgânico: corpo, subjetividade e tecnologias digitais. Rio de Janeiro: Relume Dumará, 2002.

VAZ, P. R. G. Corpo e risco. Fórum Media, Viseu, v.1, n.1, p. 101-111, 1999a. Disponível em: <HTTP: // www.eco.ufrj.br/ paulovaz/textos/corpoerisc.pdf> Acesso em 20 nov. 2002.

VIGARELLO, G. Panóplias corretoras: balizas para uma história. In: Sant'Anna, D. B. de (Org.). Políticas do corpo. São Paulo: Estação Liberdade, 1995, p. 21-38. 


\section{FROM REDEEMER SUFFERING TO \\ REDEEMER EXERCISE: A BRIEF PATH BODY}

RESUMEN: Este texto tiene como objetivo articular la práctica de ejercicios físicos, concepciones del cuerpo y tecnologías de poder. Para ello, se plantea una trayectoria del cuerpo desde las sociedades de soberanía, a través de las sociedades disciplinarias hasta las sociedades de control. En este enfoque, el concepto de tecnológia política del cuerpo se presenta como un mecanismo de poder qué viene de la interacción entre factores politícos, culturales y religiosos.

Palabras clave: Tecnología de poder. Actividad física. Cuerpo.

\section{DEL REDENTOR SUFRIMIENTO HASTA EL REDENTOR EJERCICIO: UN BREVE CAMINO DEL CUERPO}

ABSTRACT: This text aims to articulate physical exercise, conceptions of body and power technologies. For this, we outline a trajectory of the body from the societies of sovereignty, through the disciplinary societies to societies of control. In this approach the concept of political technology of the body is presented as a mechanism of power coming from the interaction between political, cultural and religious factors.

Keywords: Technology power. Physical activity. Body 